\title{
UCRL 3036
}

\section{UNIVERSITY OF CALIFORNIA}
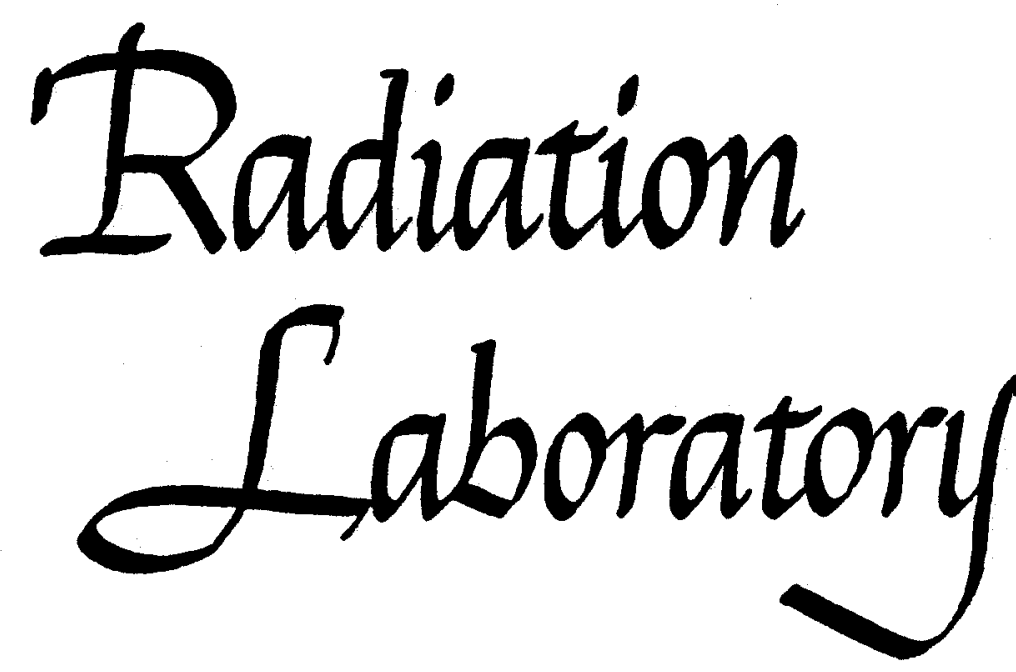

TWO-WEEK LOAN COPY

This is a Library Circulating Copy which may be borrowed for two weeks. For a personal retention copy, call Tech. Info. Division, Ext. 5545

BERKELEY, CALIFORNIA 
UCRL -3036

\section{UNIVERSITY OF CAIIFORNIA \\ Radiation Laboratory \\ Berkeley, California \\ Contract No. W-7405-eng-48}

\section{THE NEW ELEMENTS EINSTEINIUM AND EERMIUM, ATOMIC NUMBERS 99 and 100}
A. Ghiorso, S.G. Thompson, G.H. Higgins and G.T. Seaborg and

M. H. Studier, P.R. Fields, S.M. Fried, H. Diamond, J.F. Mech, G.L. Pyle, J.R Huizenga, A. Hirsch, and W.M. Manning and

C.I. Browne, H. L. Smith and R.W. Spence Los Alamos, New Mexico

June 9, 1955

Printed for the U.S. Atomic Energy Commission 
The New Elements Einsteinium and Fermium, Atomic Nambers 99 and 100

A. Ghiorso, S. G. Thompson, G. H. Higgins and G. T. Seaborg Radiation Laboratory and Department of Chemistry University of California, Berkeley, California S. M. Fried,

M. H. Studier, P.R. Flalds./H. Diamond, J.F.Meeh, G. L. Pyle, J.R. Huizenga, A. Hir sch, and $\$ / W /$ thfted/ W. M. Manning Argonne National Laboratory

Lemont, Illinoia

C. 1. Browne, H. L. Smith and R. W. Spence

Los Alamos Scientific Laboratory

Los Alamos, New Mexico

June 9,1955

This communication is a description of the results of experiments performed in December, 1952 and the following months at the University of California Radiation Laboratory (UCRL), Argonne National Laboratory (ANL) and Los Alamos Scientific Laboratory (LASL), which represent the discovery of the elements with the atomic numbers 99 and 100 .

The source of the material which was ued for the first chemical identification of these elements was the Los Alamos Scientific Laboratory which provided uranium which had been subjected to a very high instantaneous neutron flux in the "Mike" thermonuclear explosion. Initial investigations at ANL showed the presence of the new isotope Pu 2441 and investigations at ANL and LASL showed the preasence of Pa ${ }^{246}$ and $\mathrm{Am}^{2462}$ in this material pointing to the presence of neutron excess isotopes in greater abundance than expected.

This led the UCRL group to look for isotopes of tranacalifornium elements in material from the same source. Samples were subjected to chemical procedures to separate the actinide from the lanthanide fraction, ${ }^{3}$ tracer $C f^{246}$ (36-hour, 6.75-Mev alpha particle ${ }^{4}$ ) was added 
and a separation of the tripositive actinides wa effected using the cationexchange resin Dowex -50 and elution at $87^{\circ} \mathrm{C}$ with ammonium citrate solution. 5 These experiments showed the elution in a tranacalifornium position of a $6.6-\mathrm{Mev}$ alpha activity and hence proved conclusively that a new (transcalifornium) element had been found. Before the atomic number identification for the newly discovered element was completed (i. e. the correct choice between atomic numbers 99 and 100 had been made) a tentative assignment to "100 $254_{1}$ was made and this information was communicated to the ANL and LASL Laboratories. Immediately following this, further ion-exchange elution separations werecarried out at both UCRL and ANL resulting in essentially simultaneous identification of the 6.6-Mev alpha activity as belonging to the element with atomic number 99 (i.e., elution in the eka-holmium position). The results of these definitive elution experiments are shown in Fig. 1.

Further measurements on material from the same souxce by the LASL group led to the observation of a 7.1 -Mev alpha activity fat an intensity of about 4 percent of that of the $6.6-\mathrm{Mev}$ alpha activity) without chemical identification beyond proving that it was due to a transplutonium element. This 7.1-Mev alpha activity was first shown by the UCRL group in ion-exchange elution experiments of the type described above to be an isotope of element 100 (i.e. elution in the eka-erbium position just abead of the 6.6-Mev element 99 alpha activity) and was shown to have a half-life of about a day sustained by a longer-lived element 99 parent. This establishment of the isotope responsible for the 
7.1-Mev alpha activity as having the atomic number 100 was confirmed in a similar experimeat by the ANL group somewhat later. The elution data for the experiments that established this atomic number are shown in Fig. 2. The californium, berkelium, and curium radioactivities will be discus sed in a fortheoming publication.

Isotopic assignments which were made as the result of thig early work were largely confirmed by the later work on the intense neutron irradiation ${ }^{6-9}$ of $\mathrm{P}_{4}{ }^{239}$. Thus it can be said that the mass number for the 6.6-Mev 99 alpha activity is 253, corresponding to the decay sequence $C f^{253} \frac{\beta^{-}}{\sim 20 \mathrm{~d}} 99^{253}$ ( $20-\mathrm{day}, 6.6-$ Mev alpha particte), the $C f^{253}$ originating from the beta decay of $\mathrm{U}^{253}$ and daughters. Also, the mass number for the 7.1 -Mev 100 alpha activity is 255 corresponding to the decay sequence $99^{255} \underset{-30 \mathrm{~d}}{\stackrel{B^{-}}{\longrightarrow}} 100^{255}(-16$-hour, $7.1-\mathrm{Mev}$ alpha particle), the $99^{255}$ originating from the beta decay of $\mathrm{v}^{255}$ and daughters.

We auggest for the name for the element with the atomic number 99, einsteinium (symbol E) after Albert Einstein and for the name for the element with atomic number 100, fermium (symbol Fm), after Enrico Fermi.

\section{ACKNOWLEDGMENTS}

The primary acknowledgment is to the personnel of LASL for the design and construction of the thermonuclear (Mike) weapon, which gave rise to the extreme neutron flux required to produce the very heavy nuclides. We wish to thank $H$, F. Plank for his very able direction of the sampling operation. In addition the ANL group wishes to

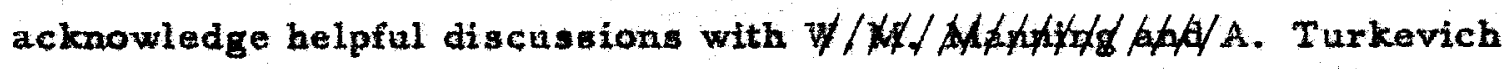


and their indebtednesa to D.F. Peppard and his group /George Mason, John Maier and Richard Wallacel, who isolated a heavy element fraction. The LASL group wishes to acknowledge their gratitude to R.A. Penneman and personnel of his group far their cooperation and the use of their pulse analyzer. The UCRL group wishes to acknowledge the cooperation of K. Street, JF., W. W.T. Crane, L.R. Zumwalt, L.B. Werner, N.E. Ballou, and I. J. Russell in providing samples, and to thank N. B. Garden, Rosemary Barrett and R.A. Glass for active assistance. $(1$.

IHess, Pyle, Fried, and Inghram, to be publiahed.

${ }^{2}$ Aaprey, Browne, Engelkemeir, Flelds, Fried, Pyle, Smith, Spence, and Stevens, to be publis bed.

${ }^{3}$ K. Street, J., and G.T. Seaborg, J. Am. Chom. Soc. 72, 2760 (1950). 4hiorso, Thompacn, Streat, Seaborg, Phys. Rev. 81, 154 (1951).

${ }^{5}$ See, e.g., Thompson, Stroet, Chiorso, and Seaborg, Fhys. Rev. 80, $790(1950)$.

6hompson, Ghiorso, Harvey, and Choppin, hys. Rev. 93, 908 (1954).

7 Harvey, Thompson, Chiorso, and Choppin, Phys. Rev. 93, 1129 (1954).

${ }^{8}$ Studier, Fields, Diamond, Mech. Friedman, Seller, Pyle, Stevens, Magnusson, and Huizenga, Phys, Rev. 93, 1428 (1954).

9. Fields. Studier, Mech, Diamond, Friedman, Magnusgon, and Huizenga, Phys. Rer. 94, 209 (1954). 


\section{FIGURE CAPTIONS}

Eig. 1. Elution of element 99 relative to californium (citrate eluant).

Fig. 2. Elution of element 100 relative to other actinide elements (citrate eluant). 


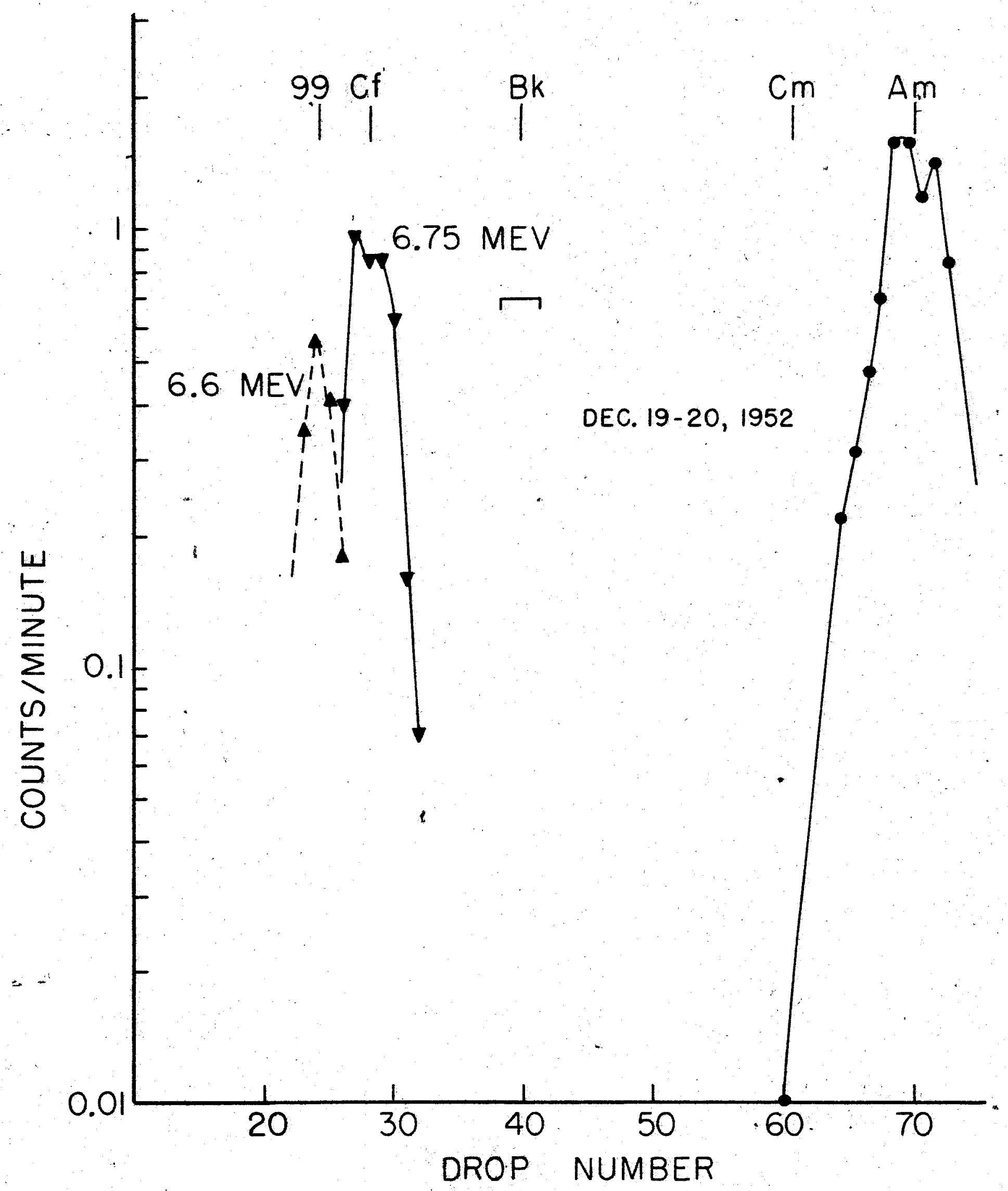




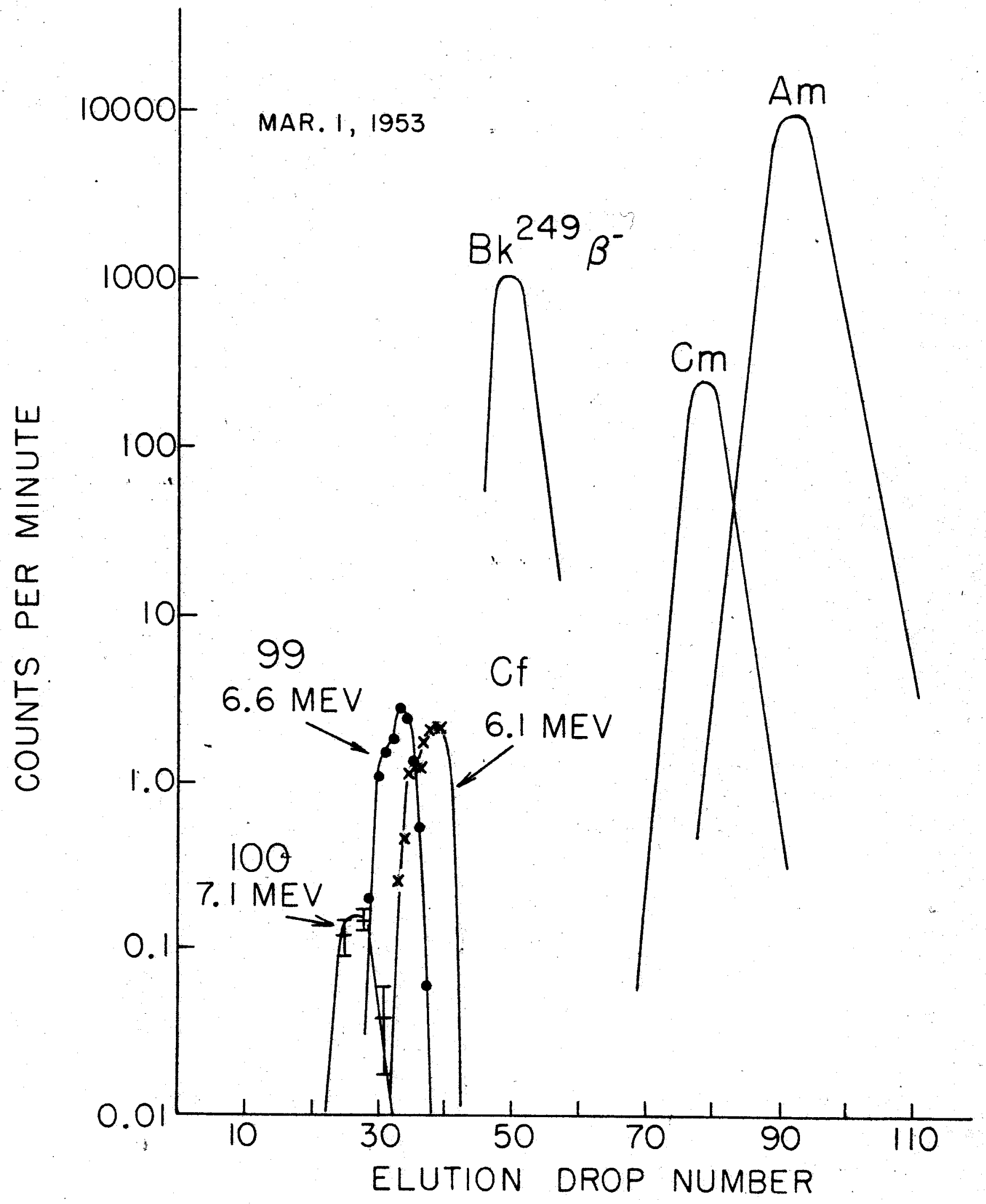

